\title{
AUTHENTICATING ANCIENT MOLECULAR STUDIES OF AVIAN AND OTHER PRESERVED HARD TISSUES.
}

COOPER, Alan*, Institute of Molecular Medicine, Oxford University, Headington, OX2 9DU, U.K.

Research on preserved human and faunal bones from a variety of European sites has revealed several simple assays that can indicate the amount preserved DNA. Both the \% nitrogen remaining in the bone (which can be measured from less than 10 $\mathrm{mg}$ of sample) and the histological appearance of the bone show considerable correlation with preserved DNA. Since both techniques are amenable to less rigorously sterile procedures than are normal for ancient DNA study they offer a relatively rapid method to survey specimens. In addition, the prolonged treatment of bones and teeth in bleach to remove contaminating DNA present in the exterior pore spaces (due to the handling of specimens) and the use of multi copy nuclear genes as PCR controls for mitochondrial sequences are evaluated.

Several molecular studies of extinct avian taxa have passed the authentication criteria of reproducibility and phylogenetic credibility. The phylogenies of the extinct giant ratite moa of New Zealand (11 spp.), and ibises and spoonbills from around the world (23 spp.) have been obtained. Both involve many extinct taxa which yield reproducible results yet show taxon specific differences. The ibis phylogeny reveals an old world - new world split and the spoonbills to be modified ibises.

Two paleoecological studies have been completed which demonstrate the power of ancient molecular studies to augment traditional paleontological investigations. In New Zealand, the molecular investigation of moa and kiwi genetic diversity has revealed the effects of an Oligocene marine transgression, and its implications for studies of other New Zealand taxa.

In Hawaii, ancient DNA studies of the endangered Laysan Duck and sub-fossil remains from lava tubes of the main islands have confirmed that relict island populations are often mis-identified as endemics following human caused extinctions, and demonstrate how ancient DNA and paleontology must be synthesised to permit adequate modern conservation planning. 